\title{
SLAC/CERN High Gradient Tests of an X-Band Accelerating Section
}

\author{
J. W. Wang, G. A. Loew, R. J. Loewen, R. D. Ruth, A. E. Vlieks \\ SLAC, Stanford University, Stanford, CA 94309 USA
}

I. Wilson, W. Wuensch

CERN, Genève 23, CH-1211

\section{INTRODUCTION}

High frequency linear collider schemes envisage the use of rather high accelerating gradients: 50 to $100 \mathrm{MV} / \mathrm{m}$ for $\mathrm{X}$ band and $80 \mathrm{MV} / \mathrm{m}$ for CLIC. Because these gradients are well above those commonly used in accelerators, high gradient studies of high frequency structures have been initiated and test facilities have been constructed at KEK [1], SLAC [2] and CERN [3].

The studies seek to demonstrate that the above mentioned gradients are both achievable and practical. There is no welldefined criterion for the maximum acceptable level of dark current but it must be low enough not to generate unacceptable transverse wakefields, disturb beam position monitor readings or cause RF power losses. Because there are of the order of 10,000 accelerating sections in a high frequency linear collider, the conditioning process should not be too long or difficult.

The test facilities have been instrumented to allow investigation of field emission and RF breakdown mechanisms. With an understanding of these effects, the high gradient performance of accelerating sections may be improved through modifications in geometry, fabrication methods and surface finish. These high gradient test facilities also allow the ultimate performance of high frequency/short pulse length accelerating structures to be probed.

This report describes the high gradient test at SLAC of an $\mathrm{X}$-band accelerating section built at CERN using technology developed for CLIC.

\section{THE ACCELERATING SECTION}

The travelling wave accelerating section has 26 regular cells and 2 coupler cells. Section parameters are summarized in Table 1. Details of the geometry of the disk loaded waveguide are given in Reference [1] which also describes the high gradient test at KEK in September 1992 of a 20 cell version of the same design.

The average and peak accelerating gradients are related to input power by the following expressions:

$$
\begin{aligned}
& \langle E\rangle[M V / m]=15 \sqrt{P_{\text {in }}[M W]} \\
& E_{P}[M V / m]=18.4 \sqrt{P_{\text {in }}[M W]}
\end{aligned}
$$

The accelerating section was made using the diamond machine and braze techniques developed at CERN for prototype CLIC accelerating sections [4]. After arrival at SLAC, the section was baked out at $250^{\circ} \mathrm{C}$ for 2 days. It was then stored under a vacuum of $10^{-9}$ Torr for nine months before being tested.

\begin{tabular}{|l|l|}
\hline Beam hole radius & $3 \mathrm{~mm}$ \\
\hline Disk thickness & $2 \mathrm{~mm}$ \\
\hline Effective length $(26+2$ cells $)$ & $.2449 \mathrm{~m}$ \\
\hline Group velocity, $\mathrm{vg}_{\mathrm{g}} \mathrm{c}$ & $1.1 \%^{*}$ \\
\hline Impedance, $\mathrm{r} / \mathrm{Q}$ & $16.0[\mathrm{k} \Omega / \mathrm{m}]$ \\
\hline Shunt impedance, $\mathrm{r}$ & $106.8[\mathrm{M} \Omega / \mathrm{m}]$ \\
\hline $\mathrm{Q}$ & $6680^{*}$ \\
\hline Attenuation parameter & $1.61[\mathrm{neper} / \mathrm{m}]^{*}$ \\
\hline Filling time, $\mathrm{t}_{\mathrm{f}}$ & $58[\mathrm{~ns}]^{*}$ \\
\hline Surface/Accelerating field & 1.9 \\
\hline
\end{tabular}

Table 1: Section Parameters (* signifies measured values).

\section{THE TEST FACILITY}

The SLAC high gradient test facility was powered by an XC-2 klystron feeding a SLED II pulse compression system. The maximum klystron power was $20 \mathrm{MW}$ with a pulse length of $1 \mu \mathrm{s}$, and the corresponding pulse compressor output was $68 \mathrm{MW}$ with a pulse length of $150 \mathrm{nsec}$. The repetition rate of the system was $60 \mathrm{~Hz}$.

The vacuum levels in the input and output waveguides and in the input beam pipe were measured. Input, transmitted and reflected RF power signals were measured with crystal detectors and captured on a 2 Gsample/sec scope. Upstream and downstream dark currents were measured with Faraday cups. The energy spectrum of the downstream dark current was measured with a spectrometer and a third Faraday cup. The level of radiation produced by the accelerating section was measured with a monitor placed in contact with the side of the accelerating section.

\section{EXPERIMENTAL RESULTS}

The accelerating section ultimately achieved an average accelerating gradient of $125 \mathrm{MV} / \mathrm{m}$ which corresponds to a peak accelerating gradient of $153 \mathrm{MV} / \mathrm{m}$ and a peak surface gradient of $285 \mathrm{MV} / \mathrm{m}$. The highest average accelerating field as function of the number of pulses is shown in Fig. 1. 10 shots at $60 \mathrm{~Hz}$ corresponds to 46 hours and the entire conditioning process took roughly two weeks. 


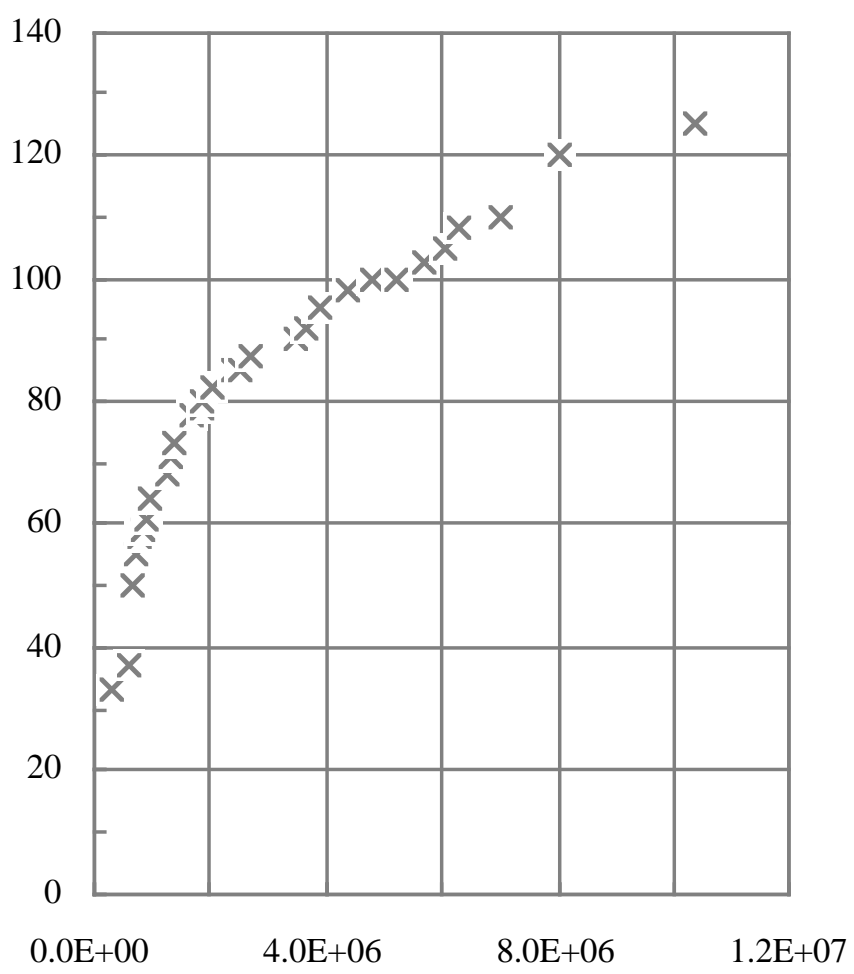

Figure 1: Highest average accelerating gradient $[\mathrm{MV} / \mathrm{m}]$ as a function of the number of pulses.

After reaching the power level corresponding to about 100 $\mathrm{MV} / \mathrm{m}$ average accelerating gradient in the section, electrical discharges occurred in both the accelerating section and the test facility components. The recovery time needed for both section and test facility component discharges contributed roughly equally to the slope of data above $100 \mathrm{MV} / \mathrm{m}$ in Fig.1. The experiment ended at $125 \mathrm{MV} / \mathrm{m}$ because the gradient in the section was improving very slowly and the klystron was nearly at its power limit.

RF power to the section was interrupted whenever the vacuum level at the section input or output rose above $10^{-8}$ Torr. After allowing time for the vacuum level to recover, RF was restarted at a reduced power level. The input vacuum level interlock was the most active during conditioning. The reflected RF power level was not used as an interlock input. Dark currents tended to be high and unstable just before a breakdown and thus were used as a rough guide for setting the rate of increase of input power.

The level of dark current as a function of accelerating gradient at different fields and stages of conditioning is shown in Fig. 2.

Throughout the high gradient tests the upstream dark current was greater than the down stream dark current. Below the dark current capture threshold of $60 \mathrm{MV} / \mathrm{m}$ the higher upstream dark current is probably due to $33 \%$ higher fields at the section input. Why the dark current capture mechanism did not lift the downstream current above the upstream at fields above the capture threshold is not understood.

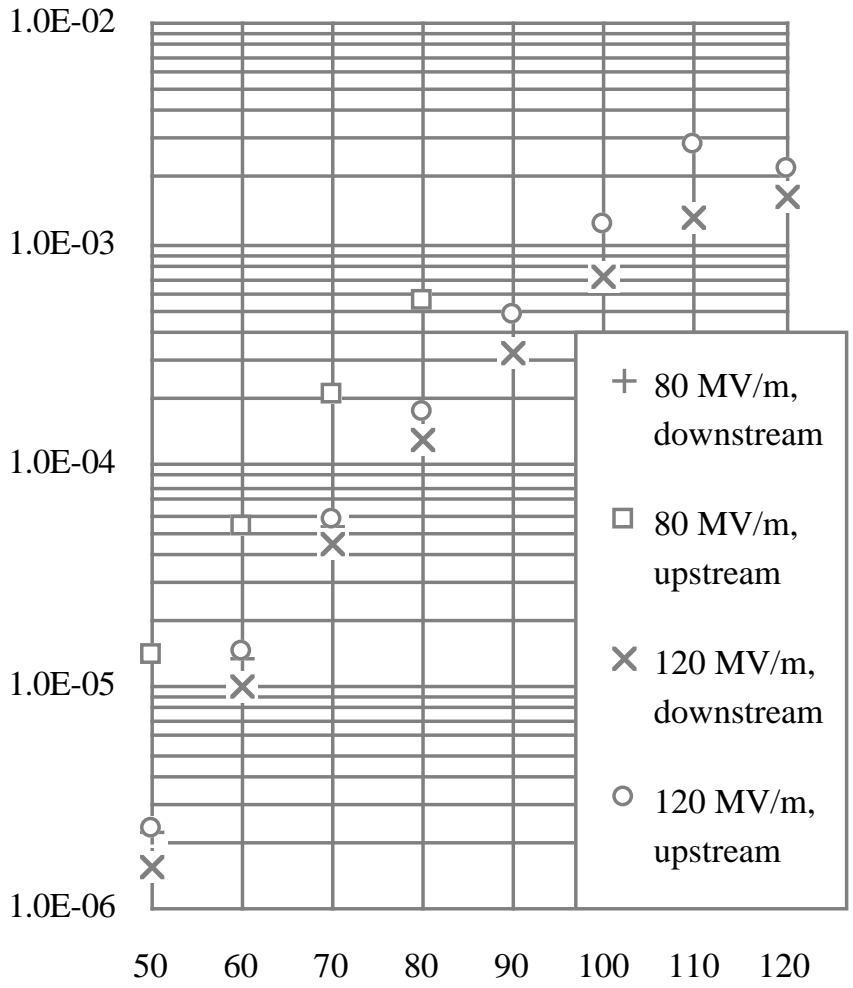

Figure 2: Upstream and downstream dark currents [A] vs. accelerating gradient $[\mathrm{MV} / \mathrm{m}]$ at various stages of conditioning - indicated by the gradients given in the legend.

The upstream dark current for a given gradient decreased as the conditioning process proceeded but the downstream dark current did not.

The downstream dark current spectrometer had a momentum acceptance $(\Delta \mathrm{p} / \mathrm{p})$ of $2 \%$. Plots of downstream dark current vs. momentum are shown in Fig. 3. The cut-off momenta of 20 and $25 \mathrm{MeV} / \mathrm{c}$ correspond to average accelerating gradients of $82 \mathrm{MeV} / \mathrm{m}$ and $102 \mathrm{MeV} / \mathrm{m}$ respectively.

Dark current as a function of frequency is shown in Fig. 4. The downstream dark current increase with increasing frequency is similar to that observed in other high gradient tests $[1,2]$.

The radiation level measured on the surface of the side of the accelerating section increases roughly exponentially with accelerating gradient as shown in Fig 5. 


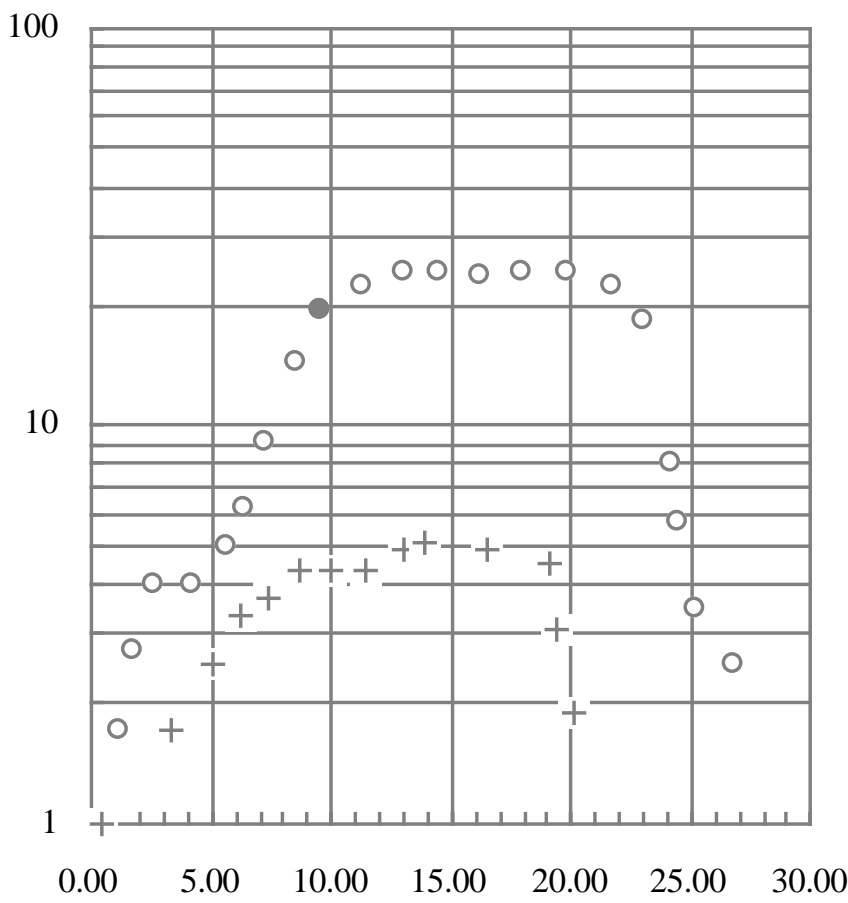

Figure 3: Dark current [pA] vs. momentum $[\mathrm{MeV} / \mathrm{c}]$. Circles are for $100 \mathrm{MV} / \mathrm{m}$ and plus signs are for $80 \mathrm{MV} / \mathrm{m}$.

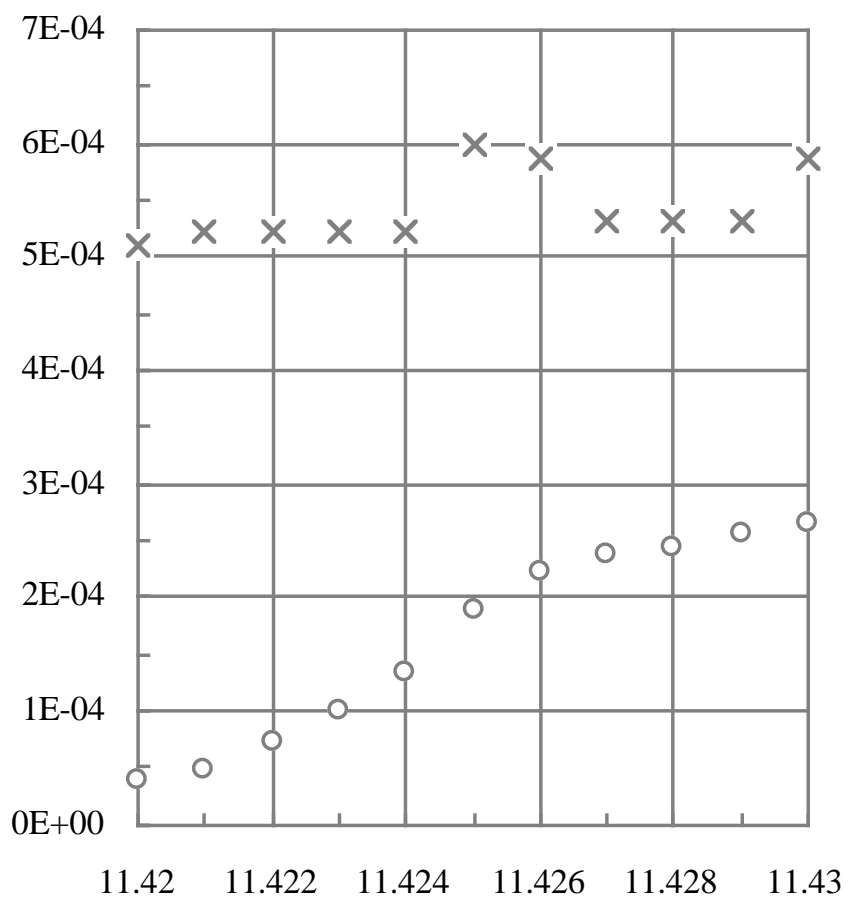

Figure 4: Dark current as a function of frequency for an accelerating gradient of $100 \mathrm{MV} / \mathrm{m}$. x's are upstream dark currents and circles are downstreamdark currents.

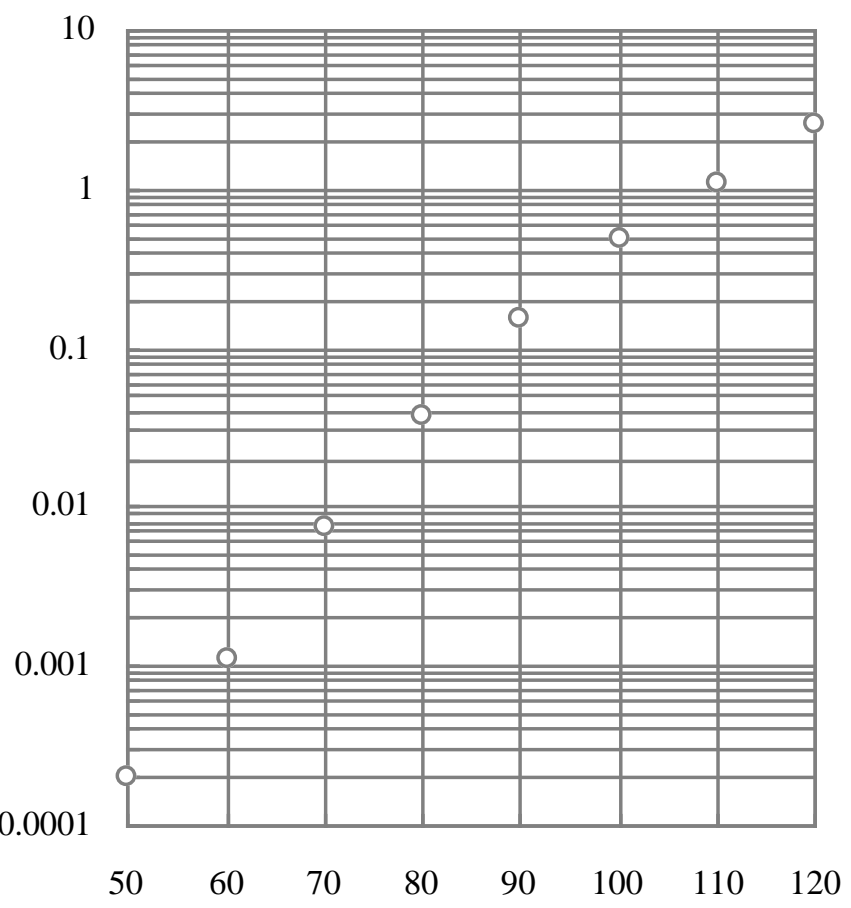

Figure 5: Radiation level [Rem/min] as a function of gradient $[\mathrm{MV} / \mathrm{m}]$.

\section{ACKNOWLEDGEMENTS}

I. W. and W. W. wish to thank C.Achard and S. Leblanc for their help in the design and fabrication of the accelerating section. They also wish to thank the NLC group for making their stay at SLAC enjoyable and successful.

\section{REFERENCES}

[1] T. Higo et.al., "High Gradient Performance of X-Band Accelerting Sections for Linear Colliders," Particle Acclerators, 1994, Vol. 48, pp.43-59.

[2] J. Wang et. al.,"High Gradient Studies on $11.4 \mathrm{GHz}$ Copper Accelerator Structures," 16th Int. Linac Conf., August 1992, Ottawa.

[3] R. Bossart et. al., "Performances Obtained with the CERN Linear Collider Test Facility (CTF)," European Particle Accelerator Conference, June 1994, London.

[4] I. Wilson, W. Wuensch, C. Achard, "The Fabrication of a Prototype $30 \mathrm{GHz}$ Accelerating Section for CERN Linear Collider Studies," EPAC, June 1990, Nice. 